\title{
A drug utilization study in glaucoma patients in ophthalmology out patient department in a tertiary care hospital
}

\author{
Kaushal B. Patel, Gurusharan H. Dumra*, Adarsh Jeet Singh, \\ Abhishek Vyas, Chetan G. Parmar
}

Department of Pharmacology, AMC MET Medical College, Maninagar, Ahmedabad 380008, Gujarat, India

Received: 23 May 2017

Revised: 02 July 2017

Accepted: 07 July 2017

*Correspondence to:

Dr. Gurusharan H. Dumra, Email: gurusharandumra@ yahoo.co.in

Copyright: (C) the author(s), publisher and licensee Medip Academy. This is an openaccess article distributed under the terms of the Creative Commons Attribution NonCommercial License, which permits unrestricted noncommercial use, distribution, and reproduction in any medium, provided the original work is properly cited.

\begin{abstract}
Background: According to World Health Organization (WHO) studies Glaucoma is a chronic progressive symptomatic disease that damages retinal cells and is one of the leading cause of preventable blindness worldwide. Availability of newer topical agents has modernized the management of glaucoma.

Methods: A prospective observational study was carried out from August 2016 to December 2016 at ophthalmology Out Patient Department of L.G General Hospital, Ahmedabad by authours after the approval of the Institutional Ethics Committee.

Results: Out of total 101 patients, 71 were males and 30 were females. Average age of patient is 54 years. Common variant of Glaucoma was Primary Open Angle Glaucoma in $57.4 \%$ of patients. Average number of drugs per prescription was 2 (45\%). Most commonly used Fixed Dose Combination was Brimonidine +Timolol Drops which was used in $87(86.1 \%)$ patients. Most commonly used adjuvant drug was Tab. Acetazolamide (60\% of patients).

Conclusions: Common variant of Glaucoma was Primary Open Angle Glaucoma in 57.4\% of patients. Most commonly used Fixed Dose Combination was Brimonidine+Timolol Drops which was used in $87(86.1 \%)$ patients and commonly used Single drug therapy is Tab. Acetazolamide in (60\% of patients).
\end{abstract}

Keywords: Angle closure glaucoma, Chronic narrow angle glaucoma, Drug utilization study, Narrow angle glaucoma, Prescription analysis, Primary open angle glaucoma

\section{INTRODUCTION}

According to World Health Organization (WHO) studies Glaucoma is chronic progressive and usually symptomatic disease that damages retinal cells and is one of the leading cause of preventable blindness worldwide. ${ }^{1}$ Approximately 60 million people are suffering from glaucoma and this figure is likely to rise to 80 million by $2020 .^{2}$ Country like India is spending $30-40 \%$ of their total health budget on drugs, some of which are inappropriate and expensive. ${ }^{3}$

It is thus essential to identify the pattern of drug use for glaucoma.
Risk factors for the glaucoma are high intraocular pressure, age more than 60 years, family history of glaucoma, systemic conditions like diabetes, heart disease, high blood pressure and sickle cell anemia, eye condition like near sightedness, and topical administration of steroids for a long time. ${ }^{4}$ It is difficult to detect optic nerve damage in early stages of the disease.

Symptoms of glaucoma are severe headache, eye pain, blurred vision, nausea and vomiting, halos around lights, redness of eye, patchy blind spots in peripheral or central vision in both eyes and tunnel vision in the advanced stages. 
Availability of newer topical agents have created new path in the management of glaucoma but the cost of these drugs pose a major hindrance to effective treatment. . $^{5-7}$

Periodical evaluation of drug utilization trends in glaucoma is important to check therapeutic usefulness, logical and safe use of drugs and to update the prescribing physicians with it. ${ }^{8}$ Very few Drug utilization studies have been done for glaucoma in India. ${ }^{9}$ The purpose of this study is to help form a database of current prescribing trends.

The aims of present study are:

- To analyze current prescribing trends in antiglaucoma drugs

- $\quad$ To identify drugs per prescription and Category wise identification of drugs prescribed

- To study frequency of combination versus single drug therapy

\section{METHODS}

The study was prospective observational study.

Study period was from August 2016 to December 2016.

The study group consists of 101 patients, either sex, diagnosed with Glaucoma at L. G. Hospital, Maninagar, Ahmedabad.

\section{Inclusion criteria}

- Patients of any age group

- Patients of either gender

- Patients treated in ophthalmology outpatient department for glaucoma

- Willingness to give written informed consent.

\section{Exclusion criteria}

- Patients who were diagnosed with other ophthalmological condition

A prospective observational Study was conducted after the approval of the Institutional Ethics Committee at a tertiary care hospital (L.G General Hospital). The study was done by the Department of Pharmacology with the help of Ophthalmology Department. All patients presenting to the Ophthalmology OPD with glaucoma related complaints and those referred from other departments have been included in the study. The diagnosis of the Glaucoma done by the senior Ophthalmologist on duty and written informed consent was taken from all participating patients. Prescriptions of all the patients attending Glaucoma OPD either self-presenting or referred by other departments of the institution were screened. The clinical, demographic and medication data was documented into case report form (CRF).

\section{RESULTS}

Out of total 101 patients, 71 were males and 30 were females (Figure 1). Average age of patients is 54 years (Figure 2). Minimum age is 17 years (1 patient) and Maximum age is 77 years ( 3 patients) for Male patients. For Female patients Minimum age is 18 years (2 patients) and Maximum age is 77 years (1 patient).

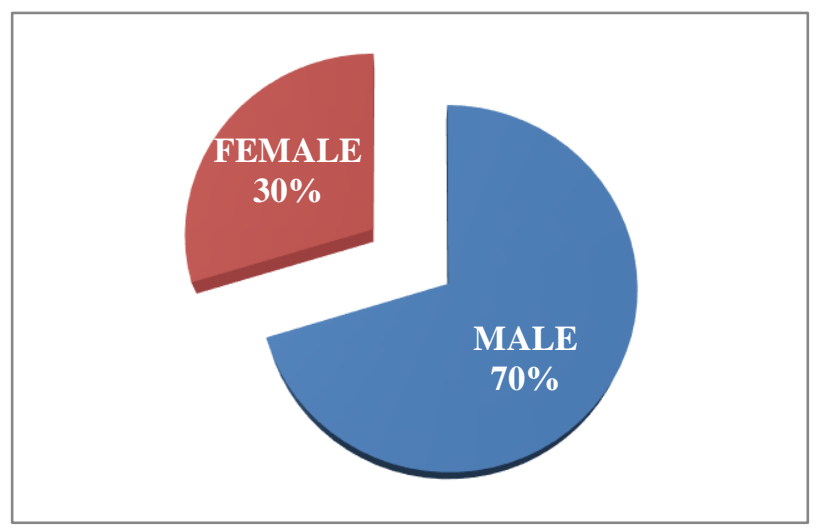

Figure 1: Gender wise distribution of glaucoma in study.

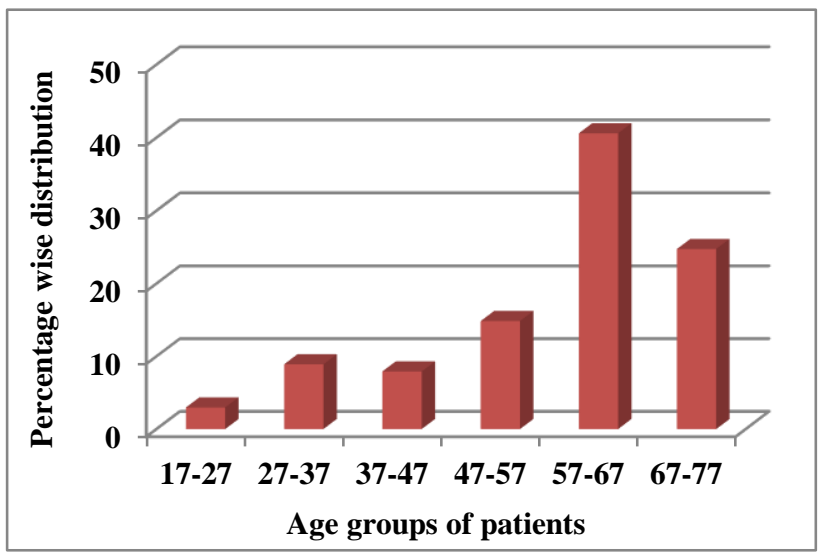

Figure 2: Age wise distribution.

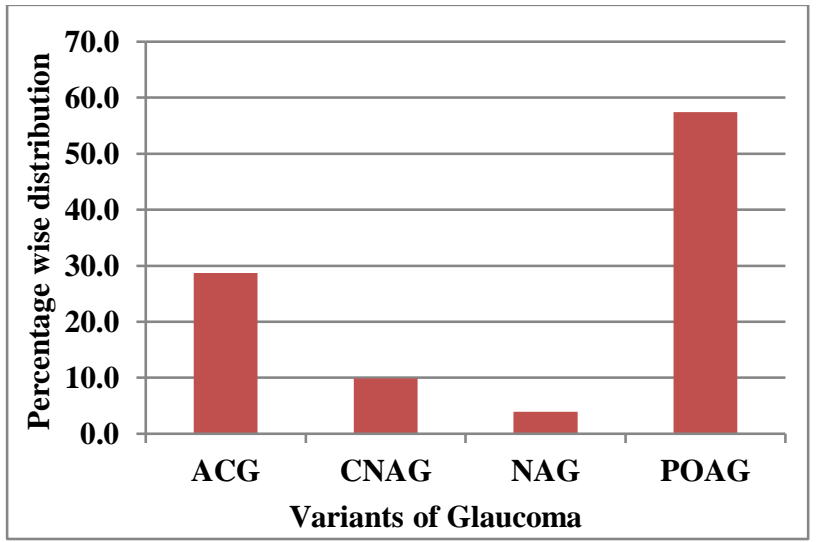

NAG- Narrow Angle Glaucoma, POAG-Primary Open angle glaucoma, ACG-Angle closure Glaucoma, CNAG-Chronic Narrow Angle Glaucoma

Figure 3: Variants OG glaucoma. 
57.4\% of patients had Primary Open Angle Glaucoma and $28.7 \%$ of patients had Angle closure Glaucoma while Chronic Narrow angle Glaucoma and Narrow angle glaucoma was found in $9.9 \%$ and $4 \%$ of the patients respectively (Figure 3).

Average number of drugs per prescription was $2(45 \%)$ (Figure 4), which includes Tab. Acetazolamide and Bimatoprost drops (19\% of Patients), Brimonidine Drops and Betaxolol Drops (13\% of patients) Tab. Acetazolamide and Pilocarpine drops (4\% of Patients).

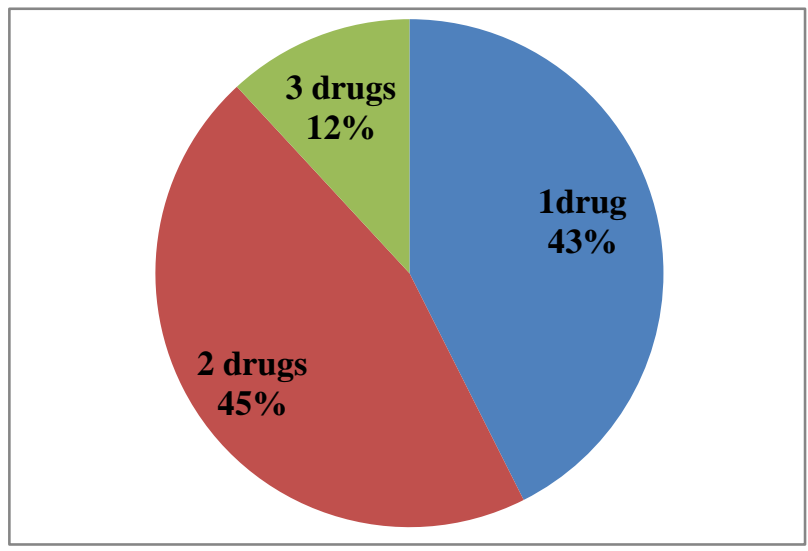

Figure 4: Total number of drugs per prescription.

Most commonly used fixed dose combination was Brimonidine + Timolol which was used in 87 (86.1\%) of patients (Table 1).

Single drug therapy includes Tab. Acetazolamide in 59 patients $(60 \%)$ and Brimonidine Drops in 8 patients $(8 \%)$. (Table 1).

Table 1: Frequency of fixed dose combination versus single drugs.

\begin{tabular}{|ll|}
\hline & \multicolumn{1}{|c|}{$\begin{array}{l}\text { Frequency } \\
\mathbf{n}=\text { number of patients }\end{array}$} \\
\hline Fixed dose combination \\
\hline Brimonidine + Timolol & 87 \\
\hline Single drugs as monotherapy \\
\hline 1) Tab. Acetazolamide & 59 \\
2) Brimonidine drops & 8 \\
\hline
\end{tabular}

\section{DISCUSSION}

After analyzing 101 prescriptions of patients suffering from glaucoma, we found male preponderance with male: female ratio of $2.4: 1$, This finding is in contradictory to findings of other such study where male: female ratio was found to be $1: 1 .^{10}$ Maximum number of patients in this study belongs to age group of 57-67 years and same age group also seen in like other study. ${ }^{10}$

Most common variant of glaucoma in this study is Primary open angle glaucoma and this result is consistent with similar kind of study. ${ }^{11}$ Average number of drugs per prescription was $2(45 \%)$ in our study, justifying on basis of such recommendation. ${ }^{12}$

Majority of patients in this study were treated with Fixed Dose Combination of Brimonidine+Timolol and most common drug as monotherapy was Tab. Acetazolamide thus the results of this drug utilization treatment/study are in accordance with the given guidelines (All India Ophthalmological Society Guideline for glaucoma treatment) which says Topical Beta blockers or Topical Prostaglandin analogues are the preferred $1^{\text {st }}$ line agents as they can lower intra ocular pressure by atleast $20 \% .^{13}$ Guidelines also suggest alpha agonist and carbonic anhydrase inhibitors can be added as second line of therapy.

\section{CONCLUSION}

In this drug utilization study for glaucoma common variant of Glaucoma was Primary Open Angle Glaucoma in $57.4 \%$ of patients. Most commonly used Fixed Dose Combination was Brimonidine +Timolol Drops which was used in $87(86.1 \%)$ patients and commonly used Single drug therapy is Tab. Acetazolamide in 59 patients $(60 \%)$. This is in accordance with All India Ophthalmological Society Guideline for glaucoma treatment and also justifies its rational use.

\section{ACKNOWLEDGEMENTS}

Authors would like to thank the Assistant Professor, Professor and Head of Ophthalmology Department, L.G. General Hospital.

Funding: No funding sources

Conflict of interest: None declared

Ethical approval: The study was approved by the Institutional Ethics Committee

\section{REFERENCES}

1. World Health Organization. The selection of essential drugs WHO technical report. Switzerland. 1977;615:36

2. An assessment of the Health and Economic Burden of Glaucoma, American Journal of Ophthalmology. Oct 2011;152(4):515-22.

3. Melrose D. Double deprivation public and private drug distribution from the perspective of the third world's poor. World Dev. 1983;11:181-6.

4. Mayo Clinic. Cited 2017 April. Available at: http://www.mayoclinic.org/diseases conditions/glaucoma/basics/risk-factors/con20024042" http://www.mayoclinic.org/diseases conditions/glaucoma/basics/risk-factors/con20024042.

5. Friedman DS, Hahn SR, Gelb L, Tan J, Shah SN, Kim $\mathrm{EE}$, et al. Doctor-patient communication, healthrelated beliefs, and adherence in glaucoma: Results 
from the glaucoma adherence and persistency study. Ophthalmology. 2008 Aug 31;115(8):1320-7.

6. Tsai JC. Medication adherence in glaucoma: approaches for optimizing patient compliance. Current Opinion in Ophthalmology. 2006;17(2):190-5.

7. Sleath AL. Covert RD, Byrd JE, Tudor G, Svarstad B. Patient-reported behavior and problems in using glaucoma medications. Ophthalmology. 2006;113(3):431-6.

8. Krishnaswamy K, Dinesh KB, Radhaiah G. A drug survey precepts and practices. Eur J Clin Pharmacol. 1985;29:363-70.

9. Dandona L, Dandona R, Srinivas M, Mandal P, John RK, McCarty CA, et al. Open-angle glaucoma in an urban population in southern India: the Andhra Pradesh eye disease study. Ophthalmology. 2000 Sep 30;107(9):1702-9.

10. Prajwal P, Rai M, Gopalakrishna HN, Kateel R. An Exploratory Study on the Drug Utilization Pattern in
Glaucoma Patients at A Tertiary Care Hospital. J App Pharm Sci. 2013;3(10):151-5.

11. Yadav AK, Patel V. Drug use in primary open angle glaucoma: A prospective study at a tertiary care teaching hospital. Indian J Pharmacol. 2013;45:11720.

12. Gilman AG, Rall TW, Nies AS. Principles of therapeutics. In the Pharmacological Basis of Therapeutics $8^{\text {th }}$ Edition, eds. New York; Pergamon Press; 1990:62-83.

13. All India Opthalmological Society. Cited 2017 April. Available at: https://www.aios.org/glaucoma.pdf

Cite this article as: Patel KB, Dumra GH, Singh AJ, Vyas A, Parmar CG. drug utilization study in glaucoma patients in ophthalmology out patient department in a tertiary care hospital. Int J Basic Clin Pharmacol 2017;6:1955-8. 